\title{
Building energy modelling for the energy performance analysis of a hospital building in various locations
}

\author{
Ioan Silviu Dobosi ${ }^{1,{ }^{*}}$, Cristina Tanasa ${ }^{2}$, Nicoleta-Elena $\mathrm{Kaba}^{3}$, Adrian Retezan $^{4}$, and Dragos Mihaila ${ }^{2}$ \\ ${ }^{1}$ S.C. Dosetimpex S.R.L., 300714 Timisoara, Romania \\ ${ }^{2}$ S.C. Daro Proiect S.R.L., 300714 Timisoara, Romania \\ ${ }^{3}$ S.C. Ambient Performer S.R.L., 305400 Jimbolia, Romania \\ ${ }^{4}$ Department of Civil Engineering and Building Services, Politehnica University Timisoara, 300223 Timisoara, Romania
}

\begin{abstract}
The building sector has been identified as having the greatest energy reduction potential and therefore represents a key factor for the European Union climate change combat objectives of achieving an $80-95 \%$ greenhouse gas emissions reduction by 2050 . Hospitals buildings represent $7 \%$ of the nonresidential building stock in the European Union and are responsible for approximately $10 \%$ of the total energy consumption in this sector. The design and construction of hospital buildings is a complex and challenging activity for all the involved specialists, especially when energy performance is one of the objectives. This paper discusses the energy performance simulation on an hourly basis of a new hospital building that was constructed in the city of Mioveni, Romania. At this stage of the study, the building energy model solely investigates the performance of the building envelope, without modelling the HVAC system. The complexity of the building model derives from the multitude of thermal zones depending on interior temperature and ventilation air changes conditions. Several simulations are performed investigating the heating and cooling energy need depending on the building location.
\end{abstract}

\section{Introduction}

The European Commission (EC) proposed a long-term policy plan as part of the European Union (EU) climate change combat action. The targets to be achieved by 2050 consist in reducing the GHG emissions by $80-95 \%$ compared to 1990 levels [1]. In 2014, an intermediate policy framework for climate and energy in the period from 2020 to 2030 was released [2]. This comes with new perspectives and aims as follows: reducing the greenhouse gas emissions by $40 \%$, increasing the share of renewable production of more than $27 \%$ and increasing the energy efficiency with $27 \%$, all compared to 1990 levels. The building sector has been identified as having the greatest energy reduction potential and therefore represents a key factor for the European Union climate change combat objectives. Hospital buildings occupy approximately $7 \%$ of the non-residential building stock in the European Union and are responsible for $10 \%$ of the total energy use in the non-residential building sector [3]. The particularity of hospital buildings is that they have a continuous energy usage throughout the year, with energy demand varying greatly depending on the functionality of each room. Hospitals require an uninterrupted power supply in order to provide reliable services 24 hours a day and they also usually have a secondary power generation system in cases of emergency [4]. The major sources of energy consumption and implicitly greenhouse gas emissions from hospitals are for medical procedures, laundry rooms, kitchens, sterilization rooms, laboratories, air conditioning, ventilation and heating [4]. According to [6], most hospitals have the following specific needs that influence the energy consumption:

- constant power requirement distributed over the course of a day and throughout the year;

- continuous requirement for air conditioning;

- often simultaneous requirement for heat and power;

- continuous hot water requirement throughout the year. In the study made by the German foundation Viamedica, the electricity and heating energy consumption per bed of a hospital building is almost as the ones consumed by two households [8]. Another study [18] made an overview on the energy in the European healthcare institution and has the following conclusions on the total energy consumption: $41 \%$ to $87.5 \%$ from the total energy consumption is related to heating, $2 \%$ to $17 \%$ corresponds to cooling and $15 \%$ to $40 \%$ is occupied by electricity for lighting and equipment. The differences between the minimum and maximum percentages are due to geographical and economical differences between countries implied in the study, age of the building, building composition and type of systems. Most of the hospitals in Europe are supplied with energy from nonrenewable sources [10]. The interest in increasing the energy efficiency of hospital buildings has gradually increased throughout time and in the last years and several studies and documents on this topic were

Corresponding author: ioansilviu@dosetimpex.ro 
developed by researchers or public organizations [7-17]. The European Healthcare Climate Council (EHCC) Europe's leading coalition of hospitals and health systems engaged to take measures as a response to the climate change combat policies [5]. During the Global Climate Action Summit that took place in San Francisco, several healthcare institutions across the globe committed to the $100 \%$ use of renewable electricity, which means a green house gas emissions reduction equivalent to the annual emissions of more than two hundred thousand cars. A study made by [9], identifies several energy saving measures, which are free or costs or have a very low investment cost and can be implemented in hospital building: efficient building management and improvement of the electricity contract conditions and replacement of the conventional lighting system with LED [9]. Thus, the energy performance and efficiency of a building is not solely related to the building envelope and systems but also depends on the user behaviour and management of the building operation. Hospital buildings have special requirements for ensuring a clean air and disease control, waste management. The design values for microclimate parameters can vary from a room to another, depending on the activity specific to each room [6]. In order to comply with the microclimatic, sanitary and hygiene requirements in hospital buildings and minimise energy waste, the use of an overall building automation/ management system can be an effective solution to increase comfort and energy efficiency in the operational building phase. The case study of the Grevena hospital in Greece [11] also shows that impressive energy saving targets can be achieved with minimum resources by implementing electrical energy policies. This paper aims at analyzing the energy performance of a hospital building located in Mioveni, Romania. To this purpose, a complex building energy model was developed and simulated using the hourly simulation tool EnergyPlus.

\section{Case study building description}

\subsection{Architectural and functional features}

The case study building is a medical healthcare institution that has a total useful area of approximately $17127 \mathrm{~m}^{2}$, covering the needs of a total number of 240 beds. Figure 1 shows the horizontal floor plan of the investigated building, which has smaller area than the ground floor, which has a rectangular shape. In Figure 2 is presented a perspective view of the hospital building. The building is vertically developed, having a basement, ground floor and six levels. The main functional area of the building is related to medical healthcare, including various specialized medical cabinets and rooms, laboratories, patients' rooms. The hospital building also includes administrative spaces, circulation spaces, waiting rooms, dressing rooms, cooking area etc. The main functionalities of each level of the hospital building are presented in Table 1.

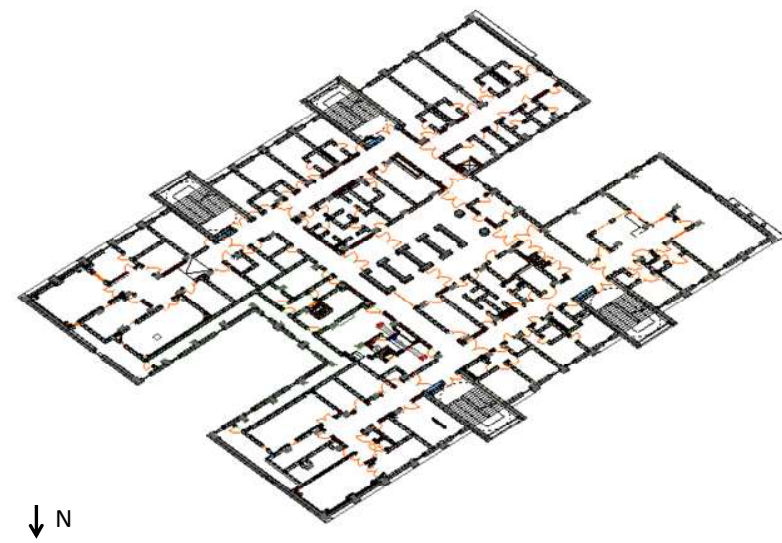

Fig. 1. Case study hospital building first floor plan.

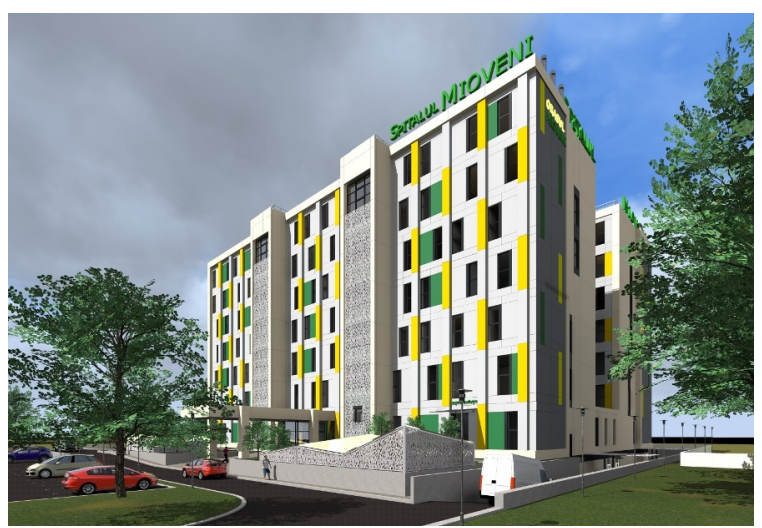

Fig. 2. Hospital building main facade.

Table 1. Building rooms destinations by floor

\begin{tabular}{|c|c|}
\hline $\begin{array}{c}\text { Type of envelope } \\
\text { element }\end{array}$ & Main Functionality \\
\hline Basement & $\begin{array}{c}\text { Morgue, Laundry, Laboratory, } \\
\text { Kitchen }\end{array}$ \\
\hline Ground floor & $\begin{array}{l}\text { EAU, Investigations, } \\
\text { Laboratory, Imaging }\end{array}$ \\
\hline $1^{\text {st }}$ floor & $\begin{array}{c}\text { Operating Block, Sterilization, } \\
\text { Intensive Care, Interventional } \\
\text { cardiology }\end{array}$ \\
\hline $2^{\text {nd }}$ floor & $\begin{array}{c}\text { Operating Block, Neonatology, } \\
\text { Maternity }\end{array}$ \\
\hline $3^{\text {rd }}$ floor & Gynecology, Pediatrics \\
\hline $4^{\text {th }}$ floor & Internal medicine \\
\hline $5^{\text {th }}$ floor & $\begin{array}{c}\text { Cardiology, Surgery and } \\
\text { Neurology }\end{array}$ \\
\hline $6^{\text {th }}$ floor & $\begin{array}{c}\text { Pharmacy, Administrative } \\
\text { spaces, Technical spaces, } \\
\text { Warehouse } \\
\end{array}$ \\
\hline
\end{tabular}

The layout of the functional areas was made in such a way as to create accessibility and good connections between them, an easy horizontal and vertical access, a clear separation of flows, a direct and as short as possible connection between all medical sectors as well 
as between them and the surgery rooms. The in-hospital circulation system is organized both horizontally and vertically. In this sense, the horizontal movement is carried out on corridors whose width allows the patients transportation with the bed or stretcher. Vertical circulation has a central node consisting of four elevators (emergency, clean patient, visitors/intervention and for garbage and medical instruments), ventilated in overpressure, two of them dimensioned so as to provide patients transportation with the stretcher. A supplementary elevator ensures a direct distribution of sterile materials from the first floor to the obstetric surgery room on the second floor and to the sterile warehouse on the ground floor. Both horizontal and vertical circulation are organized on distinct routes, represented by the circulation of patients, medical staff, technical and maintenance staff, clean or dirty medical or non-medical materials.

\subsection{Structural system and building envelope}

The structural system of the building consists in reinforced concrete pillars and diaphragms, flat roof and reinforced concrete slabs between floors. The building vertical enclosure elements are made of concrete and brickwork and the interior partitions are made from lightweight structures or glazed walls. The facades of the building consist in a ventilated wall system fixated by the masonry wall or concrete walls. The wall system includes a layer of mineral wool insulation of $10 \mathrm{~cm}$ thickness and $14 \mathrm{~cm}$ thickness in the area of the windows. The exterior facade finishes will be made of high pressure laminates and aluminium plates. The exterior fenestration consists of double glazed windows thermally insulated frames.

\subsection{Building services description}

The hospital will be equipped with complex ventilation and air conditioning systems, for complying with the admissible air purity limits provided for the hospital spaces according to the Romanian norms, as well as for providing comfort conditions for accommodating patients and conducting hospital activities. The ventilation and air conditioning of the entire hospital is achieved with the help of 17 air handling units, out of which 12 units are located at the technical level on the $6^{\text {th }}$ floor in dedicated spaces and 5 units are located in the basement of the building. All ventilation systems are to be connected to a building management system (BMS). The domestic hot water demand will be partially provided by solar collectors.

\section{Building energy modelling}

\subsection{Description of the simulation software Energy Plus}

EnergyPlus is a whole building energy simulation software that was developed in 2001 by the United
States Department of Energy (DOE) and Department of Defence (DOD) as an innovative software out of two building energy software simulations: DOE-2 and BLAST. This tool is used to model energy consumption in buildings and process loads, on an hourly basis. The targeted audience of the software are design engineers or architects that want to size heating ventilation and cooling (HVAC) equipment, perform studies on energy rehabilitation of buildings, optimize energy performance, perform parametric studies and investigate different building operation and/or energy efficiency scenarios [19]. The purpose of this study is to investigate the performance of the building envelope, without modelling the full HVAC system. For this purpose, the EnergyPlus object IdealLoadsAirSystem was used to determine the heating and cooling energy demand of the hospital building. This component supplies cooling or heating air to a thermal zone in sufficient quantity to meet the zone load. It can be regarded as an ideal unit that mixes zone air with the specified amount of outdoor air and adds or removes heat in order to meet the specified controls [24].

\subsection{Building envelope and thermal zones}

The hospital building has eight floors, including the basement and ground floor. Each floor has different zoning pattern, obtaining a total number of 116 thermal zones, depending on the heating and cooling interior air temperature and ventilation air changes. Table 2 presents the envelope elements along with the thermal characteristics and total area of each type.

Table 2. Type of building envelope elements

\begin{tabular}{|c|c|c|}
\hline $\begin{array}{c}\text { Type of envelope } \\
\text { element }\end{array}$ & $\begin{array}{c}\mathbf{U} \text {-value } \\
{\left[\mathbf{W} /\left(\mathbf{m}^{2} \mathbf{K}\right)\right]}\end{array}$ & Total area $\left[\mathbf{m}^{2}\right]$ \\
\hline $\begin{array}{c}\text { Masonry exterior } \\
\text { walls }\end{array}$ & 0.308 & 4151.9 \\
\hline $\begin{array}{c}\text { Concrete exterior } \\
\text { walls }\end{array}$ & 0.335 & 2530.1 \\
\hline $\begin{array}{c}\text { Basement exterior } \\
\text { walls }\end{array}$ & 0.342 & 1143.3 \\
\hline $\begin{array}{c}\text { Ground floor } \\
\text { Floor above } \\
\text { basement - exterior }\end{array}$ & 0.225 & 324.7 \\
\hline Terrace & 0.165 & 452.1 \\
\hline $\begin{array}{c}\text { Roof terrace } \\
\text { Exterior } \\
\text { fenestration }\end{array}$ & 0.089 & 1901.8 \\
\hline
\end{tabular}

The geometry of the building was created using the EnergyPlus plugin for Sketchup [22-23]. The ceiling height was manually introduced by the software user in order to subtract the plenum height in the thermal zones 
volume calculations. The ceiling height is $3.2 \mathrm{~m}$ for the ground floor zones and 2.8 for the rest of the zones. The zones that are technical spaces from the basement have the ceiling height equal to the floor height. Figure 3 presents a perspective of the building energy model geometry.

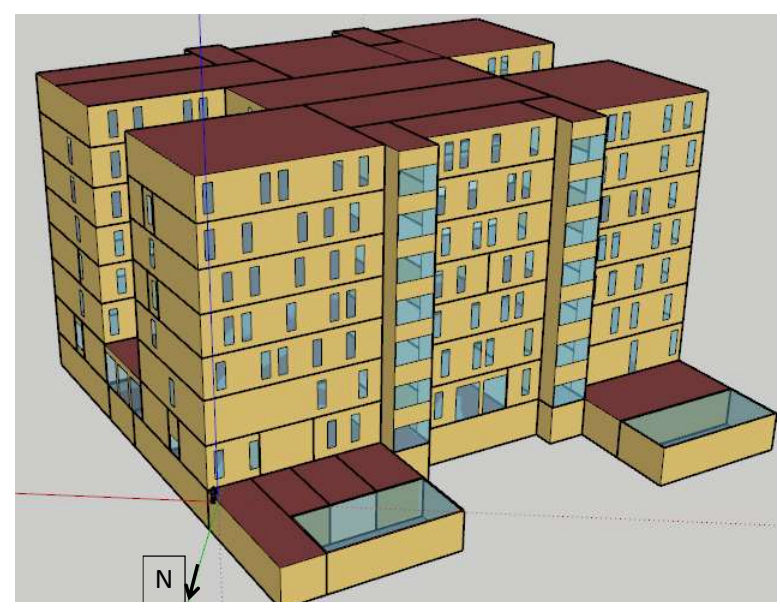

Fig. 3. Perspective view of the building energy model

\subsection{Interior temperature}

In order to assess the heating and cooling energy demands, interior air temperature was defined as control parameter for each zone through thermostats. Hospital buildings are characterised by the complexity of rooms types. The design temperature differs depending on the room destination and were defined in accordance with the romanian standards [26]. In Figure 4 we can see the design heating temperatures and the corresponding share of total building useful area. We can observe that most zones require an interior air temperature of $22^{\circ} \mathrm{C}$, representing aproximately $52 \%$ of the total building useful area, followed by zones with $24^{\circ} \mathrm{C}$.

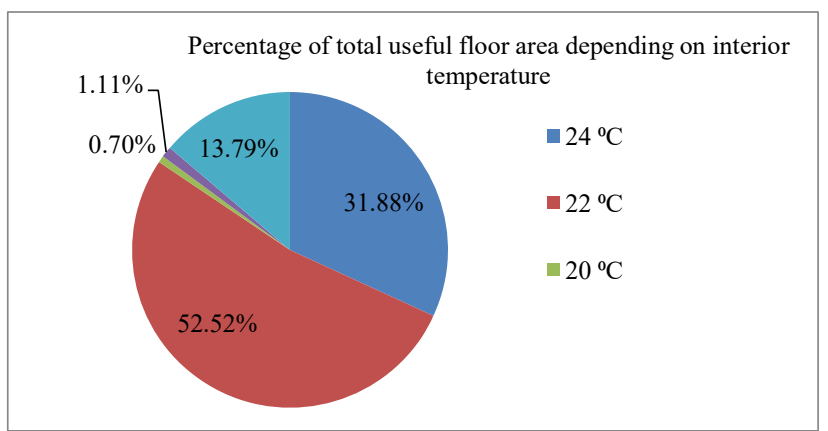

Fig. 4. Share of total useful area depending on interior temperature for heating.

The temperature for cooling was also defined depending on the zone destination. For the surgery rooms, the cooling design temperature was set to $24^{\circ} \mathrm{C}$ during the day and $25^{\circ} \mathrm{C}$ during the night. For all the other zones, the cooling temperature was set to $26^{\circ} \mathrm{C}$ during the day and $28^{\circ} \mathrm{C}$ during the night [26].

\subsection{Occupancy and lighting}

The considered internal gains for the energy simulations of the case study building consist of occupancy and lighting. Hospital buildings have an occupancy schedule for 24 hours everyday with variations on the occupancy schedules depending on the time of the day and activities. Full occupancy is possible in special cases but can rarely happen. The number of occupants was established for each thermal zone using the architectural plans and was defined as number of persons per zone floor area. The average number of persons per zone floor area of the case study building is 0.076 persons $/ \mathrm{m}^{2}$. The occupancy schedule was defined as fraction of maximum occupancy and is resented in Figure 5 for weekdays and weekend and holidays [28].

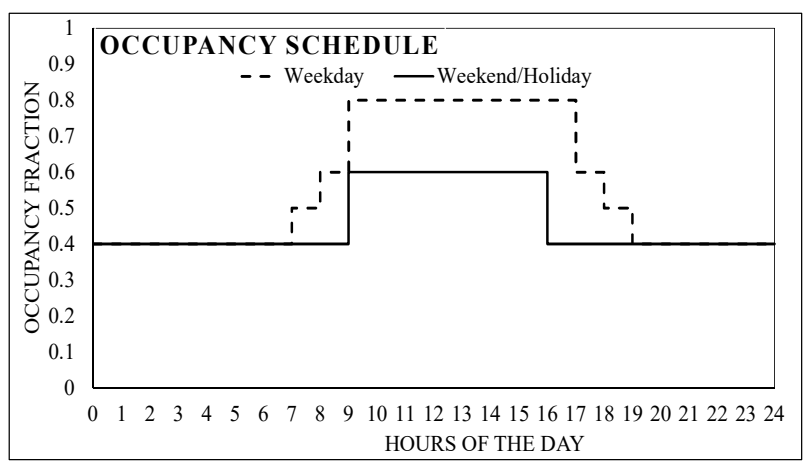

Fig. 5. Building occupancy schedule

The input data for lighting was defined separately for each thermal zone, depending on the lighting requirement established based on the room activity [30]. The building is equipped with LED lighting. The lighting power densities used in the building energy simulation are presented in Figure 6.

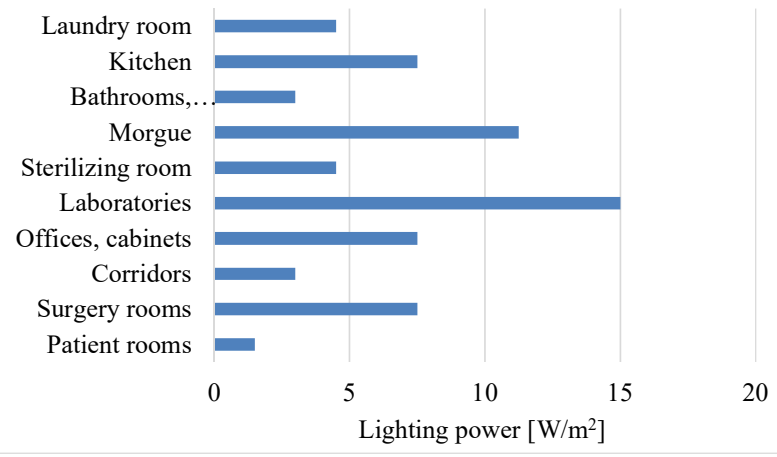

Fig. 6. Lighting power densities by room activity

\subsection{Infiltration and ventilation}

The building energy model accounts for air leakage of exterior building enclosure area. A design infiltration rate was set to $0.00203\left(\mathrm{~m}^{3} / \mathrm{s}\right) / \mathrm{m}^{2}$ for thermal zones in contact with outdoor air [28]. According to [28], the default infiltration schedule should be set equal to 1 when the fan system is off, and 0.25 when the fan system is on. This is based on the assumption that when the fan 
system is on it brings the pressure of the interior space above the pressure of the exterior, and decreases the infiltration of outside air. The building mechanical ventilation is always on, thus the infiltration schedule was set to 0.25 . The ventilation number of air changes for each zone was determined depending on the room destination in accordance with the Romanian standards [27]. Also, a heat recovery of $70 \%$ was considered in the simulation.

Table 3. Ventilation air change rates by room destination

\begin{tabular}{|c|c|}
\hline Room type & $\begin{array}{c}\text { Number of air } \\
\text { changes }\left[\mathbf{h}^{-1}\right]\end{array}$ \\
\hline $\begin{array}{c}\text { Offices, cabinets, waiting rooms, } \\
\text { corridors }\end{array}$ & 2 \\
\hline $\begin{array}{c}\text { Investigation and treatment rooms, } \\
\text { laboratories }\end{array}$ & 5 \\
\hline $\begin{array}{c}\text { Surgery rooms } \\
\text { Other rooms and corridors of surgery } \\
\text { sector }\end{array}$ & 15 \\
\hline $\begin{array}{c}\text { Patients rooms } \\
\text { Laundry room, morgue, sterilizing } \\
\text { room }\end{array}$ & 3 \\
\hline
\end{tabular}

\subsection{Weather data}

The building is located in the city of Mioveni, Arges county in Romania and corresponds to the climate zone II according to the Romanian normative [20]. The EnergyPlus tool requires hourly climate data file in order to perform the simulation. The weather data freely available for Romania is provided by ASHRAE IWEC2 (International Weather for Energy Calculations). The IWEC2 files contain 'typical' year data to be used in building energy simulation programs [21]. A 'typical' year weather data is obtained from combining multiple years' weather data for a certain location in order to best represent the pattern and range of weather parameters for the location on the long term. The weather file corresponding to the city of Bucharest was used, as it is the closest city to Mioveni and is located in the same climate zone. Also, several other simulations are performed using weather data for three representative cities in Romania. In Table 4 are listed all the cities for which the building energy model will be simulated and the corresponding climatic zone. The heating and cooling degree days of each location were taken from the EnergyPlus weather database and were calculated for a baseline temperature of $18^{\circ} \mathrm{C}$. As expected, we can see that the higher heating degree days corresponds to the climate zone III (Cluj-Napoca) location, while the lowest corresponds to climate zone I (Constanta).
Table 4. Weather characteristics

\begin{tabular}{|l|l|l|l|}
\hline \multicolumn{1}{|c|}{ Name } & $\begin{array}{c}\text { Climate } \\
\text { zone }\end{array}$ & $\begin{array}{c}\text { Cooling } \\
\text { degree days } \\
\text { [21] }\end{array}$ & $\begin{array}{c}\text { Heating } \\
\text { degree days } \\
\text { [21] }\end{array}$ \\
\hline Bucharest & II & 400 & 3030 \\
\hline Constanta & I & 411 & 2608 \\
\hline Timisoara & II & 365 & 2896 \\
\hline & & & 3596 \\
\hline Cluj-Napoca & III & 132 & \\
\hline
\end{tabular}

\section{Results}

\subsection{Energy need of the case study building}

This section describes the simulation results for the building energy model considering the baseline location (Mioveni), using the climate data available for the nearest location (Bucharest). The values of lighting energy consumption and heating and cooling energy demands is in line with the results presented in other existing research on hospital buildings $[15,16]$.

Table 5. Case study building annual energy

\begin{tabular}{|c|c|}
\hline Category & $\begin{array}{c}\text { Energy } \\
{\left[\mathbf{k W h} / \mathbf{m}^{2} \mathbf{y e a r}\right]}\end{array}$ \\
\hline Lighting & 18.68 \\
\hline Cooling & 13.00 \\
\hline Heating & 74.22 \\
\hline
\end{tabular}

These are preliminary energy need values that provide an indicator on the thermal performance of the case study building envelope, considering the indoor air requirements. Further studies are to be performed on a building energy model that also includes an accurate input data for HVAC systems and electrical equipment so as to evaluate all the energy consumption categories and to determine the primary energy need.

\subsection{Energy need comparison for various building locations}

In this section, the heating and cooling energy demands of the building were assessed by simulating the building energy model in different locations in Romania, 
described in Table 4. As we can see the energy demand to maintain the interior temperature at the defined values during the heating and cooling season, varies depending on the number of heating and cooling degree days of each location.

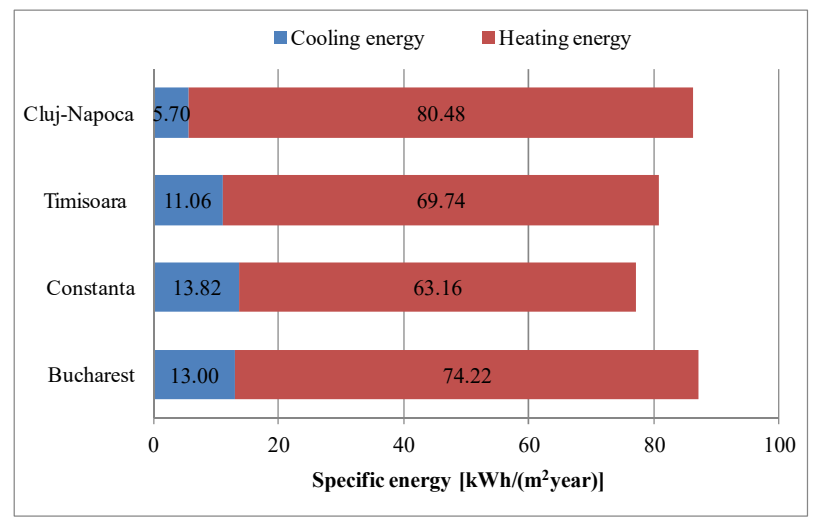

Fig. 7. Heating and cooling energy need of the case study building in different Romanian climate locations

The cooling energy demand decreases with approximately $56 \%$ if the building is located in climate zone III (Cluj-Napoca), while the heating demand increases with only $8 \%$, compared with the baseline scenario. In the situation of climate zone I, considering the location in Constanta, the cooling energy demand increases with $6 \%$ and the heating energy demand decreases with $15 \%$. It is noticeable, the difference between the results for Timisoara and Bucharest, both located in climate zone II. If the building is located in Timisoara, the heating and cooling energy demand can decrease by $6 \%$, respectively $15 \%$.

\section{Conclusions}

This paper discusses the process of building energy modelling and simulation of a hospital building, with emphasize on the building envelope and cooling and heating energy needs. The complexity of a hospital building derives from the large variety of undertaken activities and due to the very strict indoor space requirements. The development of a building energy model and simulation of such a building, even at envelope level, is a very complex activity that requires accurate information related to the thermal characteristics, building systems and operation parameters. An accurate building energy model offers the possibility to perform parametric studies. The design and construction of new hospital buildings in the Romanian public sector is currently a seldom encountered activity. The case study hospital building presented in this paper is quite an unique building project at the moment and can stand as a reference building for the further development of the built environment in the Romanian public health sector. As we can see from the results presented earlier, the transposition of the investigated building to different climatic locations leads to relatively small energy demand variation. Further studies are proposed on this case study building to investigate the entire energy consumption of the building and assess the primary energy consumption in the context of nearly zero energy building requirements in Romania.

\section{References}

1. European Comission, COM (2011) 112 final, (2004)

2. European Comission, COM (2014) 15 final, (2014)

3. Building Performance Institute Europe - Europe's buildings under the microscope, (2011)

4. https://noharm-europe.org/

5. https://noharm-uscanada.org/

6. www.siemens.com/buildingtechnologies-healthcare

7. D. Kokokotsa, T. Tsoutsos, S. Papantoniu, Advances in Building Energy Research 6:1, 159-172 (2012)

8. Viamedica Foundation (2017). Klinergie 2020: Energieeffizienz in Deutschen Kliniken. Available at: www.klinergie.de

9. J. García-Sanz-Calcedo, A. Al-Kassir, T. Yusaf, Appl. Sci. 8, (2018)

10. ResHospitals (2017). Available at: www.reshospitals.eu/about/what-we-do

11. B. Bakaimis, I. Papanikolau, Procedia Environ Sci. 38, 882-889 (2017)

12. P. Rajagopalan, H. Elkadi, Healthcare Engineering 5, 247-260 (2013)

13. M. Coccagna, S. Cesari, P. Valdiserri, P. Romio, S. Mazzacane, Journal of Environmental Science 2, 443-452 (2017)

14. N. Somboonwit, N. Sahachaisaree, Procd Soc Behv. 50, 549-562 (2012)

15. Z. Gao, Y. Li, Y. Ning, Procedia Engineer 205, 2485-2942 (2017)

16. A. Franco, M. Shaker, D. Kalubi, S. Hostettler, Sustainable Energy Technologies and Assessments 22, 92-105 (2017)

17. B.C. Singer, W.F. Tschudi, Environmental Energy Technologies Division (2009)

18. Energy in European Healthcare Institutions (2011)

19. https://energyplus.net/

20. Ordin 386/2016 pentru modificarea şi completarea indicativ C 107-2005.

21. https://energyplus.net/weather.

22. https://www.sketchup.com/

23. https://bigladdersoftware.com/projects/euclid/

24. U.S. Department of Energy. EnergyPlus Version 8.5 Documentation. Input Output Reference

25. NP 015-1997

26. EN ISO 13790-2008

27. I5-2010

28. ANSI/ASHRAE/IES Standard 90.1-2016

29. NP-061-2002 